\title{
WEIGHT TRAINING AND STRENGTH, CARDIORESPIRATORY FUNCTIONING AND BODY COMPOSITION OF MEN
}

\author{
C. M. REID, MS, Rachel A. YEATER, PhD and Irma H. ULLRICH, MD* \\ Department of Sport and Exercise Studies, *Department of Medicine, West Virginia University, Morgantown, West Virginia
}

\begin{abstract}
Forty-five men (18-35 years) trained three times a week for eight weeks to determine the effects of four constant-resistant weight training programmes on muscular strength, endurance, body composition and cardiovascular functioning. Subjects were randomly assigned to one of four programmes: Endurance (2 sets of 15 repetition maximum [RM]); Explosive (1 set of $15 \mathrm{RM}$ ); Strength 1 ( 3 sets of $6 \mathrm{RM}$ ); Strength 2 ( 1 set of $10 \mathrm{RM}$ twice weekly and 1 set of $3 \mathrm{RM}$ once weekly). All groups showed significant increases in elbow and shoulder flexion strength with elbow extension strength improved in the Explosive, Strength 2 and Endurance groups. Shoulder extension strength improved the Endurance group and in the Strength 2 group. Maximum oxygen uptake ( $\mathrm{L} / \mathrm{min})$ and $\left(\mathrm{ml} \cdot \mathrm{kg}^{-1} \mathrm{~min}^{-1}\right)$ improved significantly in the Endurance and Strength 2 groups. Lean body weight increased significantly in all groups except the Strength 1 group, but there was no change in \% fat for any group. Due to a high drop out rate $(55 \%)$ and injury related problems, the Explosive technique is not recommended. The Endurance and Strength 2 programmes were most effective for improving physiologic functioning, as assessed in this study.
\end{abstract}

\section{INTRODUCTION}

Once restricted to the realm of the male athlete, weight training is now a popular activity utilised by both men and women of all ages in an attempt to improve physical condition. However, there is still much controversy concerning the beneficial effects of weight training. Of the four weight training methods currently advocated (constant resistance, isometric, isokinetic, and variable resistance) constant resistance training is probably the most commonly utilised and prescribed method of weight training. It has also been the focus of the majority of research but as yet no constant resistance programme has been shown to be the most effective for producing optimal improvements.

It is well recognised that weight training improves strength, but the best methods for achieving improvements in strength, endurance and power performances are disputed. The possibility of using weight training to reduce body fat, and to improve maximum oxygen uptake $\left(\mathrm{VO}_{2} \mathrm{max}\right)$ has been inadequately assessed.

The present study was designed to compare the effects of four constant resistance weight training programmes on muscular strength and endurance, power, $\mathrm{VO}_{2}$ max, body composition and blood pressure response to weight training.

\section{METHODS}

Forty-five men aged 18-35 years volunteered to train three times a week over an eight-week period. Subjects were randomly assigned to one of the four weight training programmes. Prior to commencement each subject participated in a two-week familiarisation programme during which flexibility exercises and lifting techniques were taught in an attempt to reduce the risk of injury.

Subjects were tested prior to and upon conclusion of the eight-week programmes. Six different isometric strength measurements were taken in the positions listed in Table II. The cable tension testing procedures were those described by Harrison-Clarke (Harrison-Clarke, 1976). Subjects were given three attempts in each position and the highest value was recorded. Muscular endurance testing required the

Address for correspondence:

Dr. Rachel Yeater

Director, Human Performance Laboratory

West Virginia University

\#136 Coliseum

Morgantown, WV 26506-6116 subject to maintain $80 \%$ of the recorded strength measure for as long as possible in each of the six different positions used for strength testing. A stopwatch was used to measure the amount of time the effort could be maintained. All measurements were taken by the same investigator. The Margaria-Kalaman power test was used to determine leg power (Mathews and Fox, 1976). Arm power was determined using a 70\% $1 \mathrm{RM}$ (repetition max) bench press lift. A performance time analyser was used to time the lift and the distance was measured using a calibrated measuring stick. Subjects were given three attempts and the fastest time was used to determine power.

$\mathrm{VO}_{2}$ max was assessed using a modified Balke treadmill protocol. Subjects were asked not to smoke, eat or drink anything except water for two hours prior to testing. After fifteen minutes of rest, heart rate and blood pressure were recorded. Subjects were then asked to exercise on the treadmill to exhaustion. During the last minute of exercise, expired air samples were collected in 120 litre neoprene latex meteorological balloons through a low dead-space Hans Rudolf respiratory valve. The oxygen and carbon dioxide content of the expired air samples were analysed by passing a known volume of the sample through a Beckman OM-11 polargraphic and a Beckman LB-2 infra-red analyser respectively. The remainder of the gas sample was then forced through a Parkinson Cowan CD-4 gas meter to determine volume.

Body composition was assessed by determining body density using hydrostatic weighing (Warner, 1986). Residual volumes were estimated using $0.24 \times$ Vital Capacity. Five skinfold measurements were taken at: triceps, subscapular, suprailiac, abdominal, and thigh sites. Circumference measurements were made at the extended biceps, chest, abdomen, and thigh. All measurements were taken by one investigator to ensure consistency of measurement (Wilmore and Behnke, 1969). Skinfold thickness was assessed with a Harpenden skinfold caliper and three measurements were taken at each site. Measurements within one millimetre were averaged and recorded. Two measurements were taken at each circumference site and averaged.

Prior to each training session, subjects rested for a minimum of 5 minutes and resting heart rate and blood pressure were taken. Similar measurements were obtained within 1 minute after the subject completed the training session. During each session, subjects performed the following exercises on a Supra-Athletics Corporation 
Weight Machine No. 3289: (1) Leg extension, (2) Leg curl, (3) Seated leg press, (4) Calf raise, (5) Bench press, (6) Military press, (7) Latissimus dorsi pulldown, (8) Triceps extension, and (9) Biceps curl. One set of each exercise was performed before the subject commenced the second or third set as described by the group programmes. After completion of each exercise, subjects in all groups were required to record a 10 second pulse count before continuing on to the next station. Subjects were encouraged to move quickly between each exercise station although no specific rest interval was dictated.

The exercise programmes for the four groups were as follows:

Endurance. Each subject performed 2 sets of 15 repetitions of each exercise. The initial load was the 15 RM which was determined during the familiarisation period. When the subject could perform 18 repetitions of the load during the second set then the load was increased by $2.27 \mathrm{~kg}$ ( 5 pounds). Again when 18 repetitions could be performed with this load, a further $2.27 \mathrm{~kg}$ was added. This process continued throughout the length of the programme.

Explosive. Each subject performed 1 set of 15 explosive repetitions using a $40 \% 1 \mathrm{RM}$ load at each of the exercise stations. The $40 \% 1 \mathrm{RM}$ load for each exercise was determined during the familiarisation period. When the subjects could perform 18 repetitions of the exercise in the desired manner the weight was increased 5 pounds $(2.27 \mathrm{~kg})$.

Strength 1. Each subject performed 3 sets of 6 repetitions using a $6 \mathrm{RM}$ load, determined during the familiarisation period. When the subject could perform 8 repetitions during the third set the weight was increased 5 pounds. This procedure was continued throughout the length of the study.

Strength 2. Each subject performed, on the first and second training session of each week, 1 set of 10 repetitions using the $10 \mathrm{RM}$ load. As soon as 12 repetitions could be performed the weight was increased 5 pounds. During the third training session of each week, subjects performed 1 set of 3 repetitions using a 3 RM load. When 5 repetitions could be performed the weight was increased 5 pounds.

Pre- and post-training differences within each group were analysed by paired t-tests. Analysis of variance was determined using a GLM Multiple Regression analysis and a Duncans Multiple Range test was used to identify specific differences when significant $F$ values were obtained.

\section{RESULTS}

The subjects' adherence to the eight week weight training programmes is listed in Table IA. Fifty-five per cent of the subjects in the Explosive programme failed to complete the study. Subjects were required to attend at least $80 \%$ of the 24 training sessions to be included in the results (Table IB). Initial and final strength values (Table II) indicate that all groups showed a significant increase between pre- and post-training measures in elbow flexion, leg extension and shoulder flexion strength. The Endurance and Strength 2 groups showed further significant increases in elbow extension and leg flexion. The Strength 1 group increased in all areas except elbow extension where the $21 \%$ increase just failed to reach statistical significance. The Explosive group failed to show any significant increases in either leg flexion or shoulder extension strength. An analysis of variance conducted on the per cent change scores
TABLE IA

Number of subjects who embarked on (initial) and completed (final) the weight training programmes.

\begin{tabular}{lcccc}
\hline & \multicolumn{4}{c}{ Weight Training Group } \\
Totals & Endurance & Explosive & Strength 1 & Strength 2 \\
\hline $\begin{array}{l}\text { Initial } \\
(n=45)\end{array}$ & 12 & 11 & 11 & 11 \\
$\begin{array}{l}\text { Final } \\
(n=34)\end{array}$ & 11 & 5 & 9 & 9 \\
\hline$\%$ of initial & $92 \%$ & $45 \%$ & $82 \%$ & $82 \%$ \\
\hline
\end{tabular}

TABLE IB

The mean number of sessions attended by those subjects who attained $80 \%$ compliance with the programme.

\begin{tabular}{lllll}
\hline \multirow{2}{*}{$\begin{array}{c}\text { Total } \\
\text { Sessions }\end{array}$} & Endurance & \multicolumn{2}{c}{ Weight Training Group } & \\
& Explosive & Strength 1 & Strength 2 \\
\hline 24 & 21.3 & 22.2 & 22.0 & 22.7 \\
Per cent & $88.7 \%$ & $88.6 \%$ & $92.0 \%$ & $94.7 \%$ \\
\hline
\end{tabular}

TABLE ॥

Pre- and post-training strength measurements, Mean \pm SD

\begin{tabular}{|c|c|c|c|c|}
\hline \multirow{2}{*}{$\begin{array}{l}\text { Strength } \\
\text { Variable }\end{array}$} & \multirow[b]{2}{*}{$\begin{array}{l}\text { Endurance } \\
\qquad(n=11)\end{array}$} & \multicolumn{2}{|c|}{ Weight Training Group } & \multirow[b]{2}{*}{$\begin{array}{c}\text { Strength } 2 \\
(n=9)\end{array}$} \\
\hline & & $\begin{array}{l}\text { Explosive } \\
(n=5)\end{array}$ & $\begin{array}{l}\text { Strength } 1 \\
(n=9)\end{array}$ & \\
\hline \multicolumn{5}{|l|}{$\begin{array}{l}\text { Elbow } \\
\text { Flexion (kg) }\end{array}$} \\
\hline $\begin{array}{l}\text { Pre-training } \\
\text { Post-training }\end{array}$ & $\begin{array}{l}40.7 \pm 6.1 \\
44.3 \pm 6.1^{*}\end{array}$ & $\begin{array}{l}39.2 \pm 5.2 \\
47.1 \pm 9.7^{*}\end{array}$ & $\begin{array}{l}42.0 \pm 5.2 \\
45.5 \pm 6.9^{*}\end{array}$ & $\begin{array}{l}39.3 \pm 4.2 \\
43.9 \pm 6.3^{* *}\end{array}$ \\
\hline \multicolumn{5}{|l|}{$\begin{array}{l}\text { Elbow } \\
\text { Extension (kg) }\end{array}$} \\
\hline Pre-training & $34.7 \pm 7.9$ & $31.4 \pm 4.8$ & $33.4 \pm 8.1$ & $28.5 \pm 7.0$ \\
\hline Post-training & $42.2 \pm 9.3^{*}$ & $44.4 \pm 5.5^{* *}$ & $40.3 \pm 10.3$ & $35.0 \pm 10.8^{*}$ \\
\hline \multicolumn{5}{|l|}{$\begin{array}{l}\text { Leg } \\
\text { Flexion (kg) }\end{array}$} \\
\hline Pre-training & $37.0 \pm 7.9$ & $40.4 \pm 9.2$ & $35.2 \pm 5.3$ & $34.2 \pm 6.4$ \\
\hline Post-training & $44.7 \pm 8.4^{* *}$ & $42.8 \pm 8.4$ & $40.0 \pm 5.6^{* *}$ & $39.7 \pm 8.0^{* *}$ \\
\hline \multicolumn{5}{|l|}{$\begin{array}{l}\text { Leg } \\
\text { Extension (kg) }\end{array}$} \\
\hline Pre-training & $87.7 \pm 23.5$ & $86.8 \pm 5.8$ & $90.0 \pm 16.7$ & $80.5 \pm 15.8$ \\
\hline Post-training & $104.2 \pm 28.2^{* *}$ & $99.7 \pm 7.7^{*}$ & $103.6 \pm 16.4^{* *}$ & $95.5 \pm 17.8^{* *}$ \\
\hline \multicolumn{5}{|l|}{$\begin{array}{l}\text { Shoulder } \\
\text { Flexion (kg) }\end{array}$} \\
\hline Pre-training & $49.2 \pm 12.6$ & $48.0 \pm 6.5$ & $52.9 \pm 11.9$ & $47.3 \pm 10.7$ \\
\hline Post-training & $60.6 \pm 10.2^{* *}$ & $55.0 \pm 3.3^{*}$ & $64.4 \pm 9.8^{* *}$ & $58.3 \pm 10.7^{* *}$ \\
\hline \multicolumn{5}{|l|}{$\begin{array}{l}\text { Shoulder } \\
\text { Extension (kg) }\end{array}$} \\
\hline Pre-training & $49.6 \pm 13.9$ & $48.8 \pm 8.7$ & $51.8 \pm 9.1$ & $48.2 \pm 11.1$ \\
\hline Post-training & $61.4 \pm 11.4^{* *}$ & $54.6 \pm 10.6$ & $66.5 \pm 11.1^{* *}$ & $54.8 \pm 11.2$ \\
\hline
\end{tabular}

Significantly different from pre-training ${ }^{*} p<0.05,{ }^{*} p<0.01$

demonstrated no significant differences among the four groups in any of the six strength tests.

The muscular endurance results (not shown) indicated a significant $(73 \%)$ increase in post-test shoulder flexion endurance for the Strength 2 group $(21.4 \mathrm{sec} \pm 6.6$ to 37.1 sec \pm 11.5 ), while the Endurance group had a $35 \%$ increase in shoulder extension endurance (31.6 sec \pm 9.4 to $37.5 \mathrm{sec}$ $\pm 8.0)$. In contrast, there was a significant (16\%) decrease in shoulder extension endurance for the Endurance group 
(35.9 sec \pm 12.3 to $30.3 \mathrm{sec} \pm 8.1$ ). No significant differences between groups were recorded on any of the six muscular endurance tests. Table III indicates that there were no significant differences between pre- and post-test arm power scores for any group. However, the Explosive group did show a significant increase in leg power.

TABLE III

Pre- and post-training power measurements (W), Mean \pm SD

\begin{tabular}{lcccc}
\hline $\begin{array}{l}\text { Power } \\
\text { Variable }\end{array}$ & $\begin{array}{c}\text { Endurance } \\
(n=11)\end{array}$ & $\begin{array}{c}\text { Weight Training Group } \\
\text { Explosive } \\
(n=5)\end{array}$ & $\begin{array}{c}\text { Strength 1 } \\
(n=9)\end{array}$ & $\begin{array}{c}\text { Strength 2 } \\
(n=9)\end{array}$ \\
\hline $\begin{array}{l}\text { Arm } \\
\text { Power }\end{array}$ & & & & \\
$\begin{array}{l}\text { Pre-training } \\
\text { Post-training }\end{array}$ & $3.6 \pm 1.05$ & $3.0 \pm 0.4$ & $3.3 \pm 0.5$ & $2.9 \pm 0.6$ \\
Leg & $4.1 \pm 1.3$ & $3.4 \pm 0.8$ & $3.8 \pm 0.6$ & $3.7 \pm 1.2$ \\
Power & & & & \\
Pre-training & $17.2 \pm 3.5$ & $14.6 \pm 2.0$ & $15.3 \pm 2.3$ & $14.9 \pm 2.2$ \\
Post-training & $17.8 \pm 2.6$ & $16.2 \pm 1.3^{* *}$ & $16.6 \pm 1.8^{*}$ & $16.2 \pm 2.3^{*}$ \\
\hline
\end{tabular}

Significantly different from pre-training, ${ }^{*} p<0.05,{ }^{* *} p<0.01$

A number of cardiovascular changes were evident among the subjects following 8 weeks' training. $\mathrm{VO}_{2}$ max I. $\mathrm{min}^{-1}$ and $\mathrm{VO}_{2}$ max ml. $\mathrm{kg}^{-1} \mathrm{~min}^{-1}$ were significantly increased in both the Endurance and Strength 2 groups (Table IV). The Strength 1 group showed a significant 6\% increase in Treadmill time while the Strength 2 group was the only group to show a significant increase in $\mathrm{O}_{2}$ Pulse. Resting systolic and diastolic blood pressure are shown in Table V. Blood pressure was unchanged after 8 weeks weight training for all groups.

TABLE IV

Pre- and post-training maximal $\mathrm{VO}_{2}$ and treadmill time, Mean $\pm \mathrm{SD}$

\begin{tabular}{|c|c|c|c|c|}
\hline \multirow[b]{2}{*}{ Variable } & \multirow[b]{2}{*}{$\begin{array}{l}\text { Endurance } \\
\qquad(n=11)\end{array}$} & \multicolumn{2}{|c|}{ Weight Training Group } & \multirow[b]{2}{*}{$\begin{array}{c}\text { Strength } 2 \\
(n=9)\end{array}$} \\
\hline & & $\begin{array}{l}\text { Explosive } \\
(n=5)\end{array}$ & $\begin{array}{l}\text { Strength } 1 \\
(n=9)\end{array}$ & \\
\hline \multicolumn{5}{|l|}{$\begin{array}{l}\mathrm{VO}_{2} \max \\
\text { I. } \min ^{-1}\end{array}$} \\
\hline Pre-training & $3.68 \pm 0.80$ & $3.71 \pm 0.54$ & $3.68 \pm 0.73$ & $3.25 \pm 0.54$ \\
\hline Post-training. & $4.02 \pm 0.59^{*}$ & $3.84 \pm 0.38$ & $4.10 \pm 0.41$ & $3.73 \pm 0.52^{* *}$ \\
\hline \multicolumn{5}{|l|}{$\begin{array}{l}\mathrm{VO}_{2} \max \\
\mathrm{ml} \mathrm{kg}^{-1} \min ^{-1}\end{array}$} \\
\hline Pre-training & $43.3 \pm 9.7$ & $47.9 \pm 2.3$ & $47.6 \pm 10.9$ & $43.8 \pm 6.5$ \\
\hline Post-training & $47.1 \pm 77^{*}$ & $49.2 \pm 1.8$ & $52.7 \pm 7.6$ & $49.6 \pm 8.3^{* *}$ \\
\hline \multicolumn{5}{|l|}{$\begin{array}{l}\text { Treadmill } \\
\text { Time (mins) }\end{array}$} \\
\hline Pre-training & $18.1 \pm 5.1$ & $19.2 \pm 1.9$ & $19.0 \pm 4.2$ & $17.7 \pm 3.4$ \\
\hline Post-training & $18.9 \pm 4.5$ & $19.6 \pm 1.7$ & $20.2 \pm 3.9^{*}$ & $19.2 \pm 3.5$ \\
\hline \multicolumn{5}{|l|}{$\begin{array}{l}\mathrm{O}_{2} \text { pulse max } \\
\text { ml.kg } \text { man }^{-1} \min ^{-1}\end{array}$} \\
\hline $\begin{array}{l}\text { Pre-training } \\
\text { Post-training }\end{array}$ & $\begin{array}{l}19.1 \pm 4.3 \\
20.6 \pm 2.8\end{array}$ & $\begin{array}{l}18.1 \pm 2.8 \\
18.8 \pm 1.8\end{array}$ & $\begin{array}{l}18.8 \pm 3.9 \\
20.8 \pm 2.0\end{array}$ & $\begin{array}{l}16.4 \pm 2.6 \\
18.8 \pm 2.6^{* *}\end{array}$ \\
\hline
\end{tabular}

Significantly different from pre-training, ${ }^{*} p<0.05,{ }^{* *} p<0.01$

Paired t-tests revealed no significant changes for any group in per cent fat or fat weight. However, there were significant increases in lean mass for the Endurance (72.8 \pm $9.4 \mathrm{~kg}$ to $74.5 \pm 9.6 \mathrm{~kg})$, Explosive $(66.0 \pm 2.8 \mathrm{~kg}$ to $68.1 \pm$ $3.6 \mathrm{~kg})$, and Strength $2(63.6 \pm 5.0 \mathrm{~kg}$ to $66.1 \pm 6.2 \mathrm{~kg})$ groups. The Endurance and Strength 2 groups showed significant alterations in the biceps $(5$ and $7 \%$ increase,
TABLE V

Pre- and post-training resting blood pressure ( $\mathrm{mm}$ Mercury), \pm SD

\begin{tabular}{|c|c|c|c|c|}
\hline \multirow[b]{2}{*}{ Variable } & \multirow[b]{2}{*}{$\begin{array}{l}\text { Endurance } \\
\qquad(n=11)\end{array}$} & \multicolumn{2}{|c|}{ Weight Training Group } & \multirow[b]{2}{*}{$\begin{array}{c}\text { Strength } 2 \\
(\mathrm{n}=9)\end{array}$} \\
\hline & & $\begin{array}{l}\text { Explosive } \\
(n=5)\end{array}$ & $\begin{array}{l}\text { Strength } 1 \\
(n=9)\end{array}$ & \\
\hline \multicolumn{5}{|l|}{ Systolic } \\
\hline Pre-training & $122.0 \pm 6.8$ & $124.2 \pm 9.4$ & $118.4 \pm 6.9$ & $121.6 \pm 6.3$ \\
\hline Post-training & $119.8 \pm 6.0$ & $124.2 \pm 11.3$ & $119.6 \pm 6.5$ & $119.0 \pm 6.3$ \\
\hline \multicolumn{5}{|l|}{ Diastolic } \\
\hline Pre-training & $77.6 \pm 7.3$ & $74.4 \pm 6.9$ & $72.9 \pm 7.2$ & $76.2 \pm 6.0$ \\
\hline Post-training & $79.3 \pm 5.6$ & $77.2 \pm 6.5$ & $76.0 \pm 4.2$ & $77.0 \pm 5.3$ \\
\hline
\end{tabular}

respectively), thigh ( 3 and $4 \%$ increase, respectively) and chest ( 3 and $4 \%$ increase, respectively) girth measurements. The Explosive group showed significant improvements in only the biceps $(5 \%)$ and thigh $(4 \%)$ girths, while the Strength 1 group improved in only the biceps $(5 \%)$ and chest $(2 \%)$ measurements. The skinfold thickness changes were relatively consistent for all groups. The only significant reductions were in the Endurance group at the subscapula $(-8 \%)$, suprailiac $(-13 \%)$, and thigh $(-11 \%)$.

\section{DISCUSSION}

The strength results illustrated in Table II, are similar to those reported by other investigators (Berger, 1962; Boyd, 1983; Clarke, 1973, Gettman et al, 1978; Pipes, 1978). All groups showed increases in strength with the Endurance group significantly improving in all six tests. The failure of the Explosive group to show any significant increase in leg flexion and shoulder extension strength may have been related to equipment problems, as the jarring reaction of the chain was at a maximum during these repetitions. No one group experienced significantly greater strength gains than any other group which fails to support Berger's finding that the Strength 1 programme was optimal for improving strength (Berger, 1962). However, the differences in programme duration and testing procedures in Berger's study tend to make the comparison difficult.

There were very few significant improvements in relative muscular endurance in any of the four groups over the 8 week period. From a total of 21 significant strength gains across all four groups there were only two instances in which significant strength gain was matched with a significant muscular endurance increase. These results suggest that the development of muscular endurance may not be able to match that of muscular strength over an 8 week period. These results support earlier research demonstrating little change in relative muscular endurance following weight training (Anderson and Kearney, 1982; Stull and Clarke, 1970).

Theoretically, it would be expected that the explosive group would show the greatest improvement in performance power by improving not only strength but also the speed component. However, the data in Table III indicate that explosive lifting is no more beneficial than the other three weight training programmes for the development of arm power. In terms of leg power, the Explosive group did show the greatest increase although it was not significantly different from any other group. The failure of the Endurance group to show any improvement in leg power may be due to the higher pre-test values making the same magnitude of improvement more difficult for them to achieve. 
Improvements in cardiovascular measurements were seen in all groups except the Explosive group. It is known that maintaining a heart rate at approximately $70 \%$ of the maximum rate, for at least $\mathbf{2 0}$ minutes, three times a week over an 8 week period will result in improved cardiovascular functioning (McArdle et al, 1981). The average training heart rates for the groups were as follows: Endurance - 134

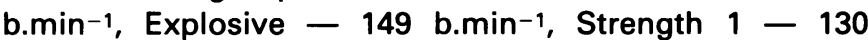
b. in $^{-1}$, and Strength $2-131$ b.min-1. These correspond to $60 \%, 73 \%, 67 \%$, and $67 \%$ of the maximum heart rates of the respective groups. Although the duration of the training sessions was not recorded, the results suggest that the Endurance, Strength 1, and Strength 2 groups maintained exercise heart rates for a sufficient period of time to improve cardiovascular functioning. The improvement of $\mathrm{VO}_{2}$ max may in part also be due to local muscular adaptations to training. Cellular alterations include an increase in the number of mitochondria and oxidative enzymes which may result in an improvement in the oxidative capacity of the muscle (Lamb, 1984). Furthermore, it is known that as local muscle mass increases, $\mathrm{VO}_{2}$ max increases hence, the increase in the lean weight, seen in all four groups, may result in a concomitant increase in $\mathrm{VO}_{2}$ max. It seems likely that the increases in $\mathrm{VO}_{2}$ max observed in this study are due to the combined effect of increased muscle mass, improved oxidative capacity of the muscle and significant cardiovascular improvements.

Resting systolic and diastolic blood pressures were not significantly altered after 8 weeks of weight training. There was however, a trend towards an increase in diastolic blood pressure for all four groups. This may have been due to the continual use of the Valsalva manoeuvre which was often observed in subjects of all groups despite admonition. The Valsalva manoeuvre, expiring against a closed glottis, results in an increase in intrathoracic pressure which causes a sharp increase in both systolic and diastolic pressure (Guyton, 1976). This emphasises the importance of having subjects use proper breathing techniques when weight lifting.

Blood pressures monitored immediately after the completion of each training session indicated that a normal blood pressure response to exercise was evident in all four groups. These results agree with the conclusion that weight training does not produce abnormal or excessive postexercise blood pressure response (Wescott and Howes, 1983).

Reductions in per cent body fat were observed for all groups with the magnitude of the reduction being similar to that reported in earlier research (Gettman et al, 1978; Pipes, 1978; Wilmore, 1974). The lack of statistical significance in relation to the per cent fat reductions may be due to fewer subjects in each training group compared with earlier research. There were significant increases in lean weight for the Endurance $(2.3 \mathrm{~kg}, 2 \%)$, Explosive $(2.1 \mathrm{~kg}, 3 \%)$, and Strength $2(2.5 \mathrm{~kg}, 4 \%)$ groups that were similar to the $4 \%$ increases in lean weight reported by Pipes (Pipes, 1978). The normal reduction in fat weight associated with weight training was evidenced in three of the four programmes. However, the Strength 1 group showed a $2 \%$ increase in fat weight. As diet was not monitored throughout this study, an increase in caloric intake may have occurred during the programme. Perhaps heavy lifting programmes, such as the Strength 1 programme, increase appetite to a greater extent than other weight training programmes (Reger, 1984).

The changes in girth measurements were relatively consistent across all groups. Increased girth measures at the extended biceps, chest, and thigh reflect the muscular hypertrophy normally associated with weight training. The significant increase in extended biceps girth for all groups is similar to that reported by Wilmore (Wilmore and Behnke, 1969). The increases in thigh and chest girth are also in accordance with previously reported data (Pipes, 1978; Wilmore and Behnke, 1969). Although all groups tended to show a reduction in skinfold thickness, only the Endurance group showed significant reductions. These occurred at the subscapular $(-8 \%)$, suprailiac $(-13 \%)$, and thigh $(-11 \%)$ locations and indicate a decrease in subcutaneous fat at the measured sites.

The high subject drop-out rate $(55 \%)$ in the Explosive group may have been the result of two interacting factors. Firstly, the actual explosiveness of the exercise produced slack in the cog and chain system of the weight machine. This limited the speed of contraction to that at which the chain was kept taut. When slack in the chain did develop, it resulted in a jarring reaction to each repetition. This produced frustration on the part of the subject and increased the possibility of injury. A common injury problem was severe head or neck pain occurring in $30 \%$ of subjects in the Explosive group. The actual aetiology of the injury was not determined but it may have been due to either the inability of the subjects to maintain correct anatomical position or elevation of blood pressures resulting from incorrect breathing techniques throughout the 15 repetitions of each exercise.

From the results of this study, explosive weight training appears to be the least effective of the four programmes. Furthermore, due to the high incidence of injury and the high subject drop-out rate it is not recommended as a suitable method of weight training. The Endurance and Strength 2 programmes appear to be the most effective and the Strength 2 programme may be the most suitable for athletic teams due to its effect on performance power. Further research into this combination-type programme, i.e. lifting maximally on one day a week and moderately on two days a week, is necessary to determine its effectiveness for improving athletic performance. Also the suitability of these weight training programmes, specifically the Endurance programme, for other populations such as the older adult needs to be determined.

\section{References}

Anderson, T. and Kearney, J. T., 1982 "Effects of three resistance programs on muscular strength and absolute and relative endurance". Res.Quart. 53: 1-7.

Berger, R. A., 1962 "Effect of varied weight training programs on strength". Res.Quart. $33(2)$ : 168-181

Boyd, J. M., 1983 "The physiological effects of two variable resistance training programs on males and females aged 18-35". Doctoral Dissertation, West Virginia University.

Clarke, D. H., 1973 "Adaptations in strength and muscular endurance resulting from exercise" . Ex.Sport Sci.Rev. Academic Press: New York.

Gettman, L. R., Ayers, J. J., Pollock, M. L. and Jackson, A., 1978 “The effect of circuit weight training on the strength, cardiorespiratory functioning and body composition of adult men". Med. and Sci.Sports 10: 171-176.

Guyton, J. E., 1976. Textbook of Medical Physiology. W. B. Saunders, Co.: Philadelphia.

Harrison-Clarke , H., 1976. Application of measurement to health and physical education. Prentice-Hall, Inc.: New Jersey.

Lamb, D. R., 1984. Physiology of Exercise: Responses and Adaptations. Macmillan Publishing Co.: New York.

Mathews, D. and Fox, E. L., 1976 "Tests and Measurements", The Physiological Basis of Physical Education and Athletics. W. B. Saunders, Co.: Philadelphia.

McArdle, W. D., Katch, F. I. and Katch, V. L., 1981. Exercise Physiology. Lea and Febiger: Philadelphia. 
Pipes, T. V., 1978 “Variable resistance versus constant resistance training in adult men". Europ.J.Appl.Physiol. 39 (1): 27-39.

Reger, B., 1984 "Exercise, Post Exercise Metabolic Rate and Appetite". Doctoral Dissertation, West Virginia University.

Stull, G. A. and Clarke, D. H., 1970 "High-resistance low repetition training as a determiner of strength and fatigability". Res.Quart. 41 (2): 189-193.

Warner, J.G., Yeater, R., Sherwood, L. and Weber, K., 1986 "A hydrostatic weighing method using total lung capacity and a small tank". Br.J.Sports Med. 20 (1): 17-21.
Westcott, W. and Howes, B., 1983 "Blood pressure responses during weight training exercises". National Strength Coaches J. Feb./Mar.: 67-71.

Wilmore, J. H., 1974 "Alterations in strength, body composition and anthropometric measurements consequent to a ten week weight training program". Med.Sci.Sport 6 (2): 133-138.

Wilmore, J. H. and Behnke, A. R., 1969 "An anthropometric estimation of body density and lean body weight in young men". J.Appl.Physiol. 27 25-31.

\section{ITEMS OF INTEREST}

Meetings of the North West division of BASM will be held on 28th April, at Blackburn Royal Infirmary, on 16th September at Bury General Hospital and on 18th Novemter at Withington Hospital. All meetings will assemble at 7.30 p.m. for an eight o'clock start. Further details from Mr. J. Sinclair, MCSP, Sports Injuries Clinic, $\mathbf{4 3}$ Hammerton Street, Burnley. Incorporated in the programme of the First World Congress of Science and Football (details in forward events) will be one day (16th April) with a special focus on "football medicine", convened by Dr. A. B. Stibbe, consultant to Ajax Amsterdam FC. The programme will culminate in a constitutional meeting of the European Society of Team Physicians in Soccer, to which any interested medical practitioner is invited. The meeting precedes the Congress Banquet and delegates may register on a one-day basis for the football medicine programme.

The National Coaching Foundation continues to promote courses for coaches on a variety of topics. A new venture is the inclusion of their courses in the Lancaster University Summer Programme, so that coaches can learn in the mornings and have the afternoons free to enjoy the nearby countryside or the leisure and sports facilities of the University. Alternative, more intensive courses will take place under the umbrella of the Loughborough University Summer School. Contact the NCF at 4 College Close, Beckett Park, Leeds LS6 30H for more details.

The next Medical Olympics will be held in Casablanca, Morocco from 5th to 11th July. For an entry form, plus details of events and registration fees please send a large SAE to Dr. David Delvin, c/o General Practitioner, 30 Lancaster Gate, London W2 3LP.

Proceedings of the Sports Medicine Conference held by the Society of Community Medicine, in association with
BASM, at UMIST last September will be available soon. Details of contents and price available from Dr. Peter Gardner of the Society of Community Medicine at 31 Battye Avenue, Huddersfield HD4 ?PW.

The attention of members is drawn to the half-page advertisement for the Sixth Congress of Sports Medicine of the A.Z.Sint-Jan to be held in Brugge, Belgium on 16th and 17th October, 1987. Two BASM members, Mr. Basil Helal and Dr. Peter Sperryn have been invited to contribute to the programme.

Mr. David Chapman, Secretary of BASM was taken ill in late February. He is back home now and I know that BASM members will join me in wishing him a full and rapid recovery.

\section{Foundation of the International Society for the Advancement of Kinanthropometry}

This society was founded at Jordanhill in July, 1986. Kinanthropometry is defined in their constitution as a scientific specialisation including, but not limited to, "auxology, physical anthropometry, human biology, physical education, sport science and several medical specialisations including paediatrics, medical genetics and geriatrics". ISAK's purpose is to "create and maintain an international network of colleagues who represent the world community transcending geography, politics and the bounds of separate disciplines." An annual membership fee equivalent to ten pounds sterling has been decided upon and questions concerning membership or other aspects of ADKA can be addressed to the Secretary-General, James A. P. Day, Department of Physical Education, The University of Lethbridge, 4401 University Drive, Lethbridge, Alberta T1K 3M4, Canada. 